\title{
JOVENS EM MOVIMENTO: MAPAS PLURAIS, CONEXÕES E TENDÊNCIAS NA CONFIGURAÇÃO DAS PRÁTICAS
}

\author{
Marilia Pontes Sposito ${ }^{1}$ \\ Elmir de Almeida ${ }^{2}$ \\ Maria Carla Corrochano ${ }^{3}$
}

\begin{abstract}
RESUMO: Este artigo analisa tendências da pesquisa sobre jovens como atores coletivos, nas formas plurais de ação na esfera público-política. As modalidades de prática foram agregadas em três eixos: aquelas derivadas da condição estudantil; as que incidem sobre as culturas juvenis; e os movimentos de ação direta, ao lado dos associativismos de base territorial e de mobilizações a partir das identidades. Baseou-se em textos acadêmicos elaborados entre 2006 e 2018, período de intensa visibilidade de práticas e conflitos protagonizados por jovens no Brasil. Evidenciam-se formatos plurais, conexões e tendências nas práticas coletivas juvenis, considerando tanto as alterações conjunturais quanto as diversas temporalidades dos processos de mobilização.
\end{abstract}

Palavras-chave: Jovens. Conflitos sociais. Movimentos sociais. Identidades.

\section{YOUTHS ON THE MOVE: PLURAL MAPS, CONNECTIONS AND TRENDS IN THE SETTING OF PRACTICES}

\begin{abstract}
This article analyzes trends in the research on youths as collective actors, in plural forms of action in the public-political space. The modalities of practices were aggregated around three axes: those derived from the student condition; those that affect youth cultures; and direct-action movements, alongside territorial-based associationism and identity-based mobilizations. The analysis focuses on academic texts written between 2006 and 2018, a period of high visibility of practices and conflicts concerning youth leadership in Brazil. It becomes evident that there are plural forms, connections, and displacements in young people's collective practices, considering both the conjunctural changes, and the various temporalities of the mobilization processes.
\end{abstract}

Keywords: Youth. Social conflicts. Social movements. Identities.

Este artigo é resultado do projeto de pesquisa: O campo de estudos de juventude no Brasil e suas interfaces com a educação e o trabalho: balanço e perspectivas da produção acadêmica - 2007-2016, coordenado por Maria Carla Corrochano, e financiado pelo Conselho Nacional de Desenvolvimento Científico e Tecnológico (CNPq).

1.Universidade de São Paulo - Faculdade de Educação - São Paulo (SP), Brasil. E-mail: mpsposito@gmail.com

2. Universidade de São Paulo - Faculdade de Filosofia, Ciências e Letras de Ribeirão Preto - Departamento de Educação, Informação e Comunicação - Ribeirão Preto (SP), Brasil. E-mail: elmir@ffclrp.usp.br

3.Universidade Federal de São Carlos - Departamento de Ciências Humanas e Educação - Centro de Ciências Humanas e Biológicas Sorocaba (SP), Brasil. E-mail: carlacorrochano@gmail.com 


\title{
JÓVENES EN MOVIMIENTO: MAPAS PLURALES, CONEXIONES Y TENDENCIAS EN LAS CONFIGURACIONES DE SUS PRÁCTICAS
}

\begin{abstract}
RESUMEN: Eso artículo analiza las tendencias en la investigación sobre los jóvenes como actores colectivos en formas plurales de acción en el ámbito público-político. Se agruparon las modalidades de prácticas en tres ejes: las derivadas de la condición estudiantil; las que afectan las culturas juveniles; y los movimientos de acción directa, juntamente con los asociacionismos de base territorial y las movilizaciones basadas en identidades. El análisis se fundamenta en textos académicos escritos entre 2006 y 2018, un período de intensa visibilidad de las prácticas y conflictos que tubieron jóvenes al frente en Brasil. Se presentan múltiples formatos, conexiones y desplazamientos en las prácticas colectivas de jóvenes, llevando en cuenta tanto los cambios coyunturales como las diversas temporalidades de los procesos de movilización.
\end{abstract}

Palabras-clave: Jóvenes. Conflictos sociales. Movimientos sociales. Identidades.

\section{Apresentação}

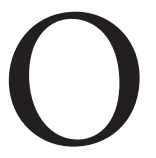

s estudos sobre juventude no Brasil coincidem com o advento dos movimentos universitários estudantis nos anos 1960, expressos, sobretudo, nos trabalhos de Marialice Foracchi (1965; 1972). Essas produções dialogam com as primeiras rebeliões observadas no início do século XX e com as várias formas do protesto político estudantil na América do Sul durante a vigência dos regimes militares.

As análises que se debruçaram sobre o tema, nas três últimas décadas, responderam, de modo geral, a um duplo desafio: de um lado, superar certas ênfases dominantes nos estudos que vincularam os jovens aos problemas sociais (ABRAMO, 1997); de outro, investigar como novas formas de sociabilidade e percursos juvenis no interior de processos de mutação social indicavam a emergência de conflitos sociais nas sociedades complexas, os quais combinavam tanto lutas materiais contra a desigualdade como conflitos pós-materiais, expressando a importância dos campos simbólicos e culturais (MELUCCI, 2001; TOURAINE, 2006).

As formas da ação coletiva e do protesto político de jovens devem ser compreendidas no quadro de mudanças importantes observadas nos últimos anos, como é o caso brasileiro. Tais formas de ação vão de um breve ciclo de prosperidade, ainda que marcado pela manutenção de padrões elevados de desigualdade e por índices crescentes de violência, até seu esgotamento após 2012, expresso nos baixos índices de crescimento e na estagnação da economia, cujas consequências afetam, de maneira mais aguda, os segmentos juvenis. Embora sem desconsiderar esse quadro, é preciso ponderar que as relações entre conjunturas econômico-políticas e a capacidade de ação da sociedade e de seus grupos não são lineares; ou seja, não se pode deduzir, de modo imediato, possibilidades ou impasses que descortinam o conflito social a partir de análises macroeconômicas, desprezando significativas mediações político-culturais.

Nos últimos anos, a polarização política, a emergência de organizações e grupos com orientações conservadoras, liberais e autoritárias trouxeram novos desafios para a investigação sobre as modalidades de ação coletiva de jovens. Esse quadro se torna mais complexo quando consideradas as inflexões e rupturas presentes após as eleições presidenciais de 2018, configurando, na acepção de 
Bringel (2018) e Bringel e Pleyers (2019), a consolidação do neoliberalismo, conduzindo à constituição de pautas regressivas e a acentuação de desigualdades sociais.

Por tudo isso, a partir de alguns eixos aglutinadores dos interesses de pesquisa, busca-se, neste artigo, situar algumas tendências e avanços nos estudos dos jovens como atores coletivos, além de constituir um conjunto de questões e hipóteses que poderão ser consideradas como desafios à continuidade desse processo de conhecimento.

A primeira linha de investigações recobre a permanência dos estudos que privilegiaram a condição estudantil como elemento aglutinador de movimentos e consequente conflito político. Embora tenha se observado um período de latência nos anos finais do século XX, as mobilizações recentes estimularam uma produção importante que amplia o escopo dos estudos tradicionais.

A segunda linha diz respeito aos estudos das denominadas culturas juvenis, investigadas no Brasil a partir dos anos 1990, que demonstraram certa continuidade e descortinaram novos desafios, quer seja pela permanência dessas formas agregadoras de práticas coletivas, quer seja pela constituição de novas temáticas e formatos do ativismo juvenil.

Finalmente, a terceira linha dialoga com as formas organizativas de jovens não necessariamente articuladas à condição estudantil, mas ligadas a temáticas e repertórios de ação consolidados tanto no campo dos movimentos de tradição socialista como aqueles de feitio autonomista e da ação direta em suas várias expressões. Integram esse bloco, também, as lutas em torno do reconhecimento e das identidades (gênero, diversidade sexual, étnico-raciais), bem como as iniciativas de organização da juventude rural.

Cada um desses eixos não pretende ser examinado de modo exaustivo nos moldes dos tradicionais Estados da Arte, mas como recurso analítico para percorrer as práticas coletivas em sua historicidade. A análise foi construída a partir da produção acadêmica ${ }^{1}$ em um período de intensa visibilidade de práticas e conflitos protagonizados pelos jovens brasileiros (2006 a 2018). Contudo, no interior de cada um dos eixos a serem apresentados, o ciclo de protestos configurado a partir de 2013 constituiu uma inflexão importante na reflexão, quer pela visibilidade, quer pelo aparecimento de novos formatos aglutinadores da ação coletiva de jovens, que continuam a impactar as análises desenvolvidas.

\section{Um Marcador do Confronto Político e Sua Visibilidade: as Jornadas de Junho de 2013 e os Jovens}

O reconhecimento da presença dos jovens nas manifestações observadas em junho de 2013 pontuou, de maneira mais ou menos evidente, as análises que a partir daí foram empreendidas, incentivando a produção por novas interpretações.

Embora os jovens fossem protagonistas relevantes, não se verificava, nesses eventos, uma agenda configurada como juvenil, uma vez que grande parte das questões presentes no campo público-político incidia sobre problemas dos moradores das grandes cidades e emitia críticas a iniciativas dos governos federal e municipais voltadas para os grandes eventos em detrimento dos investimentos em políticas públicas essenciais, tais como educação e saúde. Somava-se a esse quadro a crítica à corrupção e aos agentes políticos, revelando descrença e distanciamento das instituições que organizam o sistema político no país. As análises iniciais acentuaram o caráter da novidade nos formatos e práticas organizativas juvenis, sobretudo a partir da liderança inicial protagonizada pelo Movimento Passe Livre (MPL) (GOHN, 2013; 2014) e, também, pelo uso intensivo das ferramentas das redes sociais no âmbito da Internet, como o Facebook e o Twiter. De modo 
menos frequente, os episódios de violência protagonizados por grupos, entre os quais os Black Blocs, também foram considerados, mas pouco investigados em sua continuidade (SOLANO et al., 2014; BUCCI, 2016).

Em análises posteriores, verifica-se que houve, também, visões muito contrastantes dos eventos de 2013 e de suas consequências. Bringel (2018) e Bringel e Pleyers (2019) assinalam a importância de uma compreensão que retenha os elementos processuais que orientam o processo histórico, propondo a consideração de temporalidades mais alargadas dos conflitos sociais e dos rumos incertos da democratização da sociedade brasileira. As orientações plurais presentes nas jornadas de 2013 se desdobraram na constituição de novos movimentos, tradicionalmente discretos ou inexistentes na cena pública pelo seu feitio e agrupados no espectro considerado de direita, o que inclui conservadores, fundamentalistas, autoritários e liberais, apresentando-se, nos dias atuais, como desafios para alargar a compreensão das formas coletivas de ação dos segmentos juvenis.

Por outro lado, o momento caracterizado pelo ciclo de protestos demanda também a continuidade das análises, pois, como afirma Pineda, a estrutura das oportunidades políticas, analisada por Tarrow e Tilly (2016, p. 196), "não é uma realidade 'externa' aos sujeitos coletivos e, como tal, não está à margem dos processos cognitivos e interpretativos construídos por seus integrantes, ou seja, os processos de construção de sentido" (tradução livre) ${ }^{2}$. Se a noção de repertórios da ação coletiva (autonomista, socialista e patriótico), desenvolvida e problematizada por alguns autores (ALONSO; MISCHE, 2017; BRINGEL, 2017; BRINGEL; PLEYERS, 2019; MENDONÇA; COSTA, 2018), ajuda-nos a compreender as constelações que podem ter agrupado os jovens, é preciso reconhecer, como afirma Mendonça (2017), algumas questões que demandam maior aprofundamento, tais como: uma incursão crítica ao conceito de identidade, na medida em que o conflito pode pressupor a desidentificação (REGUILLO, 2017); a disseminação de formas mais individualizadas de engajamento político, nem sempre perfiladas em torno desses repertórios; e, finalmente, a transformação das unidades interativas diante do crescente uso das tecnologias de informação e de comunicação. O autor aponta, também, a importância da investigação sobre os diversos sentidos que perfilam a própria noção de democracia presente entre os ativistas (MENDONÇA, 2018, p. 18).

\section{Ocupações e Coletivos: Continuidades e Rupturas nas Lutas Estudantis}

Se o olhar para a face mais visível dos movimentos sociais constitui tendência da produção no tema (MELUCCI, 2001; BRINGEL, 2009) pode-se dizer que, nas pesquisas sobre o movimento estudantil, tal aspecto torna-se mais evidente. Desde os clássicos estudos sobre os universitários e seu reconhecimento como atores relevantes na conjuntura que marcou os anos da ditadura, entre os anos de 1960 e 1970 (FORACCHI, 1972; SANFELICE, 1986; CARRANO, 2002), é em torno dos momentos de confronto político que se concentra boa parte das análises. Sabe-se pouco, porém, sobre as continuidades e descontinuidades, os fluxos e refluxos do movimento nos diferentes períodos (BRINGEL, 2009).

As ocupações estudantis em 2015 e 2016 fazem parte dos momentos de confronto no espaço público, representando o que Bringel (2009) e Gohn (2017) denominam novo ciclo da participação estudantil no Brasil. Se, até então, a visibilidade das ações estudantis coletivas estava fortemente centrada no Ensino Superior, nesse novo ciclo, as primeiras irrupções são protagonizadas por estudantes do Ensino Médio.

A percepção de sua importância revela-se no expressivo conjunto de artigos, dossiês e livros, alguns produzidos quase de modo simultâneo à deflagração das primeiras ações estudantis (CAMPOS et al., 2016), bem como na presença do tema em congressos e eventos acadêmicos e políticos. De modo geral, os estudos incidiram sobre dois momentos das ocupações (GROPPO, 2018): em um primeiro momento, 
ocupações protagonizadas por estudantes do segundo ciclo do Ensino Fundamental e do Ensino Médio, que aconteceram entre 2015 e 2016 em São Paulo, Goiás, Rio Grande do Sul e Ceará, com ações contrárias a políticas educacionais de caráter estadual; e, em um segundo momento, ocupações que se iniciaram nas escolas do Paraná, em outubro de 2016, disseminando-se por quase todos os estados, tendo demandas dirigidas à esfera federal e, nessa incursão, contando com a participação de estudantes universitários. $\mathrm{O}$ estopim foi a Medida Provisória n. 74 (MP74/2016), com a proposta de Reforma do Ensino Médio, seguida da emenda do teto de gastos em educação, saúde e seguridade social por vinte anos, aprovadas no governo Temer.

O predomínio do olhar para as ocupações como um fenômeno potente, representativo de um novo ciclo de lutas no campo da educação (GOHN, 2017), em especial em função de seu formato, é revelador do reconhecimento de sua importância, mas não apenas: há uma concentração das análises em torno da face mais visível do fenômeno, quando ruas e escolas são ocupadas.

Ao lado das análises que enfatizam o potencial criativo das ações estudantis, algumas reflexões também buscam compreender, de maneira mais ampla, o contexto que possibilitou o sucesso (ou não) das ocupações nos diferentes estados, tomando-as como representativas de uma nova relação entre Estado e sociedade civil, por meio da qual as interações são marcadas por formas de ação coletiva mais confrontacionais, como ação direta, desobediência civil e a própria ocupação de instituições e equipamentos.

Além da ênfase da adoção da ocupação como estratégia mobilizadora, os elementos de valorização da horizontalidade, a ausência de lideranças definidas e o uso intensivo de Novas Tecnologias de Informação e Comunicação (NTIC) podem ser considerados tributários do próprio movimento estudantil em outros períodos e países. As análises de Mesquita (2003; 2008) sobre formas emergentes de ação coletiva no interior do próprio movimento estudantil universitário e de Bringel (2009) sobre os ciclos de protestos estudantis e a retroalimentação com outros movimentos e lutas sociais, como uma das especificidades dos movimentos estudantis, contribuem para essa percepção.

Ainda que boa parte da produção reconheça a importância da tradução para o português da cartilha "Cómo tomar un colégio", realizada pelo Coletivo Mal Educado (São Paulo), em 2011, e as inspirações nos movimentos estudantis da Argentina e do Chile, além das interfaces com o Movimento Passe Livre e as jornadas de junho de 2013, ainda carecem de aprofundamento as inter-relações de diferentes tempos, contextos, sujeitos e movimentos. A influência menos visível de outros coletivos, como cursinhos populares (BARROS, 2017) e grêmios (GROPPO et al. 2017), para a deflagração das ações mobilizadoras ainda é pouco considerada.

A recusa e a desconfiança dos participantes das ocupações em relação a entidades estudantis tradicionais, partidos políticos, sindicatos, organizações e movimentos consolidados, inclusive de jovens, também são documentadas. Estão menos presentes análises que considerem o caráter ambíguo e complexo dessas relações, incorporando o grau de porosidade e as diferenças entre as ocupações em unidades escolares diversas nas interações com esses atores organizados da sociedade civil

A prática das ocupações também não pode ser desvinculada de alterações significativas no perfil dos estudantes, na educação básica ou superior, nos últimos anos. Nessa perspectiva, ainda que predomine um olhar mais generalizante sobre os(as) “ocupas", há análises que empreendem esforços para a compreensão desses sujeitos, seja como uma primeira geração de jovens e adolescentes de camadas populares que vivenciam, de maneira exclusiva, a condição estudantil (CORTI et al., 2016), seja como estudantes trabalhadores e trabalhadores do futuro (CATINI; MELLO, 2016). As importantes presença e atuação das meninas, tanto nas manifestações de rua como no interior das ocupações, evidenciadas pela imprensa de grande circulação, bem como pela mídia alternativa, também foram objeto de algumas produções, que destacaram a relevância do olhar a partir de uma perspectiva de gênero ou interseccional (CASTILHO; ROMANCINI, 2018; BARBOSA; 
BRUM, 2018; LEITE, 2017). Um olhar a partir dos meninos e da construção das masculinidades nesse contexto, no entanto, fica restrito à dimensão da divisão de tarefas no interior das unidades ocupadas.

A organização interna das ocupações, com a constituição de comissões responsáveis pelo cotidiano, realizando tarefas como alimentação, limpeza, segurança, comunicação e relações externas, e sem divisões marcadas pelo gênero, além da prática de rodas de conversa, oficinas e debates sobre temas que interessavam os estudantes, são analisadas como possibilidades de aprendizado, formação política e ressignificações do espaço da escola e da universidade (GROPPO et al. 2017). Para além disso, aprofundando o olhar para os sentidos do estar junto nesses momentos, a análise de Medaets et al. (2018) enfatiza a importância da dimensão afetiva e da criação de vínculos que fortaleçam tanto o engajamento político quanto os posicionamentos e enfrentamentos dos jovens em relação a outras dimensões da vida, em especial a da família.

Nesse sentido, caberia registrar a relevância de uma perspectiva analítica mais aprofundada para a dimensão do cotidiano nessas emergentes modalidades de ação, tais como as ocupações, que, apesar do uso intensivo das redes on-line, existe e se fortalece nas redes off-line, nas ruas, mas também no estar junto diário e nos pequenos coletivos, o que sinalizaria um diálogo enriquecedor com a produção teórica sobre movimentos sociais.

Há um reconhecimento da possibilidade de renovação do movimento estudantil a partir das ocupações, presente em algumas análises (MESQUITA, 2003; RATTO et al., 2017). Mesquita chamava atenção, no início dos anos 2000, para as possibilidades de construção de uma "nova sociabilidade militante" no interior do movimento estudantil, considerando não só a crise de representatividade das entidades tradicionais, mas "as novas sociabilidades emergentes no meio juvenil" (MESQUITA, 2003, p. 119).

Mais recentemente, algumas análises identificam a ampliação da presença de coletivos autônomos, informais e não institucionalizados, sobretudo entre os estudantes universitários, o que parece sinalizar a disseminação de novas formas de mobilização. São coletivos voltados para a questão étnico-racial, constituídos por jovens negros e negras, o que pode ser relacionado a uma das consequências pouco exploradas e recentes das políticas afirmativas de acesso ao Ensino Superior público (OLIVEIRA, 2018), além de outras questões identitárias, como gênero e orientação sexual (AMARAL, 2014). Em suas reflexões, Amaral (2014) destaca como esses atores enfrentam não apenas os limites da militância estudantil tradicional no encaminhamento de suas questões, mas também do próprio ativismo LGBT+ clássico, que, na perspectiva dos próprios coletivos, desconsidera os múltiplos e heterogêneos sujeitos que fazem parte da militância.

A maior presença dessas novas modalidades de ação também tem repercutido nas relações com diferentes esferas de gestão da universidade. Pesquisa realizada por Medeiros et al. (2017) sobre coletivos estudantis autônomos evidencia a criação de novas instâncias deliberativas na universidade pública, com objetivo de contemplar causas específicas dos coletivos ali existentes, como a definição de direitos diante de situações de racismo, machismo, desrespeito e homofobia. Esse é um estudo emblemático acerca de uma questão que se apresenta como desafio não apenas no âmbito da gestão, tal como problematizado pelos autores: como avançar na compreensão desses novos desenhos de ação coletiva que se disseminam entre estudantes, seja na escola básica, seja na universidade?

Se a visibilidade das ocupações tomou conta de boa parte das análises, sabe-se que novos desenhos de ação não começaram e não terminarão nelas. As análises das modalidades de lutas protagonizadas por estudantes no espaço da universidade já começam a tornar mais visíveis esses novos formatos, como os coletivos, que podem dialogar com as representações estudantis tradicionais, mas não se confundem com elas, emergindo, em muitos casos, a partir da percepção dos limites dessas últimas. Na produção sobre as ações coletivas dos estudantes da escola básica, no entanto, o olhar para esses novos formatos, para além do estudo das ocupações, é quase inexistente. 


\section{Das Culturas Juvenis aos Coletivos de Jovens}

Nos anos finais da década de 1980, diante da escassa visibilidade dos conflitos estudantis, constata-se a emergência de uma vertente de pesquisas voltada para os agregados de jovens produtores de culturas ou estilos estéticos. A partir de aportes teórico-metodológicos das culturas juvenis das Ciências Sociais norteamericanas, dos Estudos Culturais do círculo de Birmingham sobre as subculturas e pós-subculturas juvenis (FEIXA PAMPOLS; NOFRE, 2012), de marcos analíticos dos estudos socioculturais latino-americanos (REGUILLO, 2000) e, ainda, de subsídios teóricos dos novos movimentos sociais (SPOSITO, 1993), pesquisadores brasileiros investigaram como localmente os jovens se apropriavam de objetos, bens materiais e simbólicos, postos globalmente em circulação pelos meios de comunicação, para criarem estilos estéticos distintos, manifestarem-se culturalmente e firmarem pertenças em territórios da vida cotidiana e áreas públicas do espaço citadino (ALMEIDA, 2009).

Durante os anos 2000, as culturas juvenis e os grupos de estilos, bem como suas práticas culturais e formas de ação, continuaram a obter a atenção da pesquisa acadêmica, seja pela retomada de questões anteriormente apreciadas, a partir de novos enquadres teóricos, seja a partir da delimitação de novos problemas e indagações sobre os agregados e as identidades coletivas juvenis já abordados ou emergentes no espaço público.

O movimento hip-hop continuou a ser foco de pesquisa, a exemplo do estudo de Moreno e Almeida (2017), que, direcionando a análise para as relações de interdependência estabelecidas entre jovens rappers e políticos profissionais de partidos, sindicatos e governos, deslindaram o conjunto diversificado de práticas políticas e culturais, visando dar visibilidade ao movimento hip-hop na esfera pública de cidade do interior paulista. Por outro lado, o estudo também delimitou questões que conduzem à problematização das injunções postas às relações entre os movimentos sociais e o sistema institucional de representação política no aprofundamento da democracia participativa na realidade brasileira.

As culturas juvenis de teor autoritário e violento, inicialmente investigadas por Costa (1993) com foco nos "carecas do subúrbio", pouco sensibilizaram a produção nos últimos vinte anos. Todavia, Possas e França (2009), tomando como referência um crime de ódio ocorrido em $2000^{3}$, em território de sociabilidades da comunidade gay na região central da cidade de São Paulo, analisaram como episódios de violência praticados por "skinheads paulistas" contribuem para a estruturação de noções de gêneros, condicionam a participação e a gestualidade de mulheres jovens "carecas" e, ainda, ampliam os conflitos e a violência simbólica e física praticada pelos "carecas" contra "minorias sociais". A exígua produção de conhecimento sobre o movimento dos "carecas" ou de grupos assemelhados deixou à sombra os elementos das sociabilidades de segmentos jovens que reiteram o que Dubet (1987) denominou condutas de crise.

Mais recorrentemente, nos anos 2010, a pesquisa que se voltou às culturas juvenis ampliou seu repertório empírico-analítico para compreender as práticas culturais e as formas de os jovens se insurgirem coletivamente no cenário socioespacial e político da cidade. Caldeira (2012, p. 32) abordou a mobilidade espacial e as intervenções de "pixadores", rappers, traceurs (praticantes de parkour), entre outros grupos, em áreas públicas da cidade de São Paulo, compreendendo-as como formas de ação política, sobretudo de jovens do sexo masculino, moradores das periferias, que, ao se apropriarem do espaço urbano, recriam-no, dão "nova visibilidade às camadas subalternas" e reclamam a cidade como um direito.

Fenômeno recente, pouco investigado, são os chamados "rolezinhos", ocorridos no fim de 2013. Pautados nas redes sociais por jovens envolvidos com o "funk ostentação" (que buscam a inclusão social mediante o consumo de marcas de "grife"), aqueles encontros se deram em shopping centers situados em bairros periféricos de grandes cidades do país, lugares ocupados pelos "rolezeiros" em busca de lazer, de se 
darem a ver e circularem. Interpretados como insurgências, atos de protestos ou contestação política, os "rolês" deram visibilidade e reatualizaram o debate público sobre a "questão urbana", na medida em que os "fluxos" e atritos por eles provocados chamaram atenção para a negação do direito à cidade aos jovens moradores das periferias de grandes centros urbanos (PINHEIRO-MACHADO; SCALCO, 2014; CALDEIRA, 2014; PEREIRA, 2016).

Em análises dos “rolezinhos", Pereira (2016) considera que esses fenômenos evocariam a perspectiva de uma "cidadania insurgente", tal como definida por Holston (2013). Já Pinheiro-Machado e Scalco (2018), ao acompanharem jovens envolvidos nesses eventos em Porto Alegre, em perspectiva longitudinal, identificaram que muitos deles, sob os feitos da crise que encolhe as possibilidades de inclusão via consumo, diante do drama da violência urbana e da segurança pública e por aspirarem condições de vida mais dignas, aderiram a fileiras do pensamento conservador e, com um "desalento" e uma aposta no "último recurso", perfilaram-se aos segmentos bolsonaristas nas eleições de 2018 (PINHEIRO-MACHADO; SCALCO, 2018, p. 58).

McRobbie e Garber (2003), Reguillo (2000) e Weller (2005) constataram a marginalidade ou a posição subordinada das jovens mulheres no interior das culturas juvenis. Os trabalhos de Facchini (2011) e Ramos (2017) analisaram, respectivamente, como as "minas do rock", e as jovens hip-hoppers e funkeiras, em interações on-line e off-line, buscam superar a subordinação do feminino em grupos de estilos, construindo espaços e formas autônomas de ação, de maneira a problematizar questões relativas à mulher, ao feminino, ao corpo da mulher, bem como questões de gênero - seja tecendo laços com redes e frentes de mulheres, seja pelo envolvimento com a cena internacional de mulheres que articulam o punk-rock, ou, ainda, pela configuração de coletivos de mulheres para dar publicidade a suas vozes. Contudo, ainda persiste a "dívida pendente" (REGUILLO, 2000) na produção do conhecimento sobre as relações entre os gêneros, bem como sobre a masculinidade hegemônica e as novas masculinidades nas culturas e nos estilos juvenis, a partir de uma perspectiva intersecional.

Há décadas, as culturas juvenis vêm ancorando, teórica e metodologicamente, estudos sobre as formas plurais de os jovens se agregarem. Inegavelmente, essa noção tem servido de recurso heurístico para a produção do conhecimento das ações coletivas juvenis não vinculadas aos movimentos estudantis. Contudo, como salientaram Feixa Pampols et al. (2018), os jovens não constroem e vivenciam as culturas juvenis em tempo integral, pois as mutações contemporâneas, materiais e imateriais, que transversalizam a sua experiência, promovem inflexões e impulsionam esses atores a forjarem novas formas de agregação e modos de agir coletivamente no espaço público, a partir de expressões culturais ou artísticas.

As novas possibilidades de ação dos jovens no espaço público, por meio de produções culturais, são apreendidas nos estudos que buscam analisar os chamados "coletivos". A emergência e a multiplicação desses agrupamentos juvenis, ao obterem reconhecimento no mundo acadêmico e também junto às instituições do sistema político e de organizações da sociedade civil, têm conduzido pesquisadores dos estudos da juventude a esforços de classificação desses novos formatos aglutinadores, em virtude da heterogeneidade de suas configurações e formas de ação (BORELLI; ABOBOREIRA, 2011; NOVAES; ALVIM, 2014; GOHN, 2017).

As inflexões assinaladas acima marcam estudos como os de Aderaldo (2017), que explorou os itinerários de jovens, com inserções em movimentos de luta popular, suas relações ambivalentes com ONG e atores governamentais, integrantes dos Coletivos de Vídeo Popular (CVP) da cidade de São Paulo. Almeida e Penzin (2018) examinaram coletivos envolvidos com linguagens literárias e produtores de saraus que diversificam e reinventam as formas de ocupação do espaço público em Belo Horizonte. Perez e Souza (2017) analisaram um amplo e diversificado conjunto de coletivos juvenis inseridos no tecido urbano de Teresina, sobretudo os produtores de práticas artístico-culturais, a partir de diferentes vinculações a outras organizações atuantes na cidade, enfatizando suas ações a partir de marcadores sociais e de gênero. 
As experiências analisadas indicam algumas questões a serem enfrentadas pela pesquisa: ainda é preciso maior rigor teórico no uso da categoria "cotidiano" no estudo dos coletivos juvenis, de modo a esmiuçar como essa dimensão da experiência social ancora a conformação daqueles agregados e de suas formas de agir; constituem desafio à investigação os modos como, no interior dos agregados juvenis, seus integrantes operam com as relações de gênero e, também, as novas masculinidades. Torna-se pertinente maior investimento na investigação sobre a diversidade na apropriação criadora do espaço citadino, reatualizando a questão urbana a partir de novas demandas e necessidades; mas, sobretudo, seria necessário perscrutar como esses agrupamentos se dispõem a tecer redes de ação conjunta, entre eles e com outros atores, a partir de temas convergentes na esfera público-política.

\section{Movimentos, Organizações e Associativismos}

Um conjunto de pesquisas desenvolvidas, sobretudo, a partir dos anos 2000 procurou investigar modos de ação coletiva de jovens que não estivessem gravitando em torno dos tradicionais movimentos estudantis ou no interior das culturas juvenis. Ainda que com pouca frequência, tais pesquisas incidiram sobre movimentos e organizações de feitio autonomista ou de tradição socialista, que privilegiaram formas de ação direta. Nessa moldura destacam-se os estudos sobre o Movimento do Passe Livre (MPL) e, com menor frequência, os estudos sobre o Levante Popular da Juventude (LPJ).

Sousa (2014), estudando organizações de jovens no sul do país, verifica algumas proximidades entre esses grupos, como:

a insatisfação com os caminhos políticos permitidos pelas instituições democráticas e, em contrapartida, a procura por opções diferentes para orientar suas formas de atuação nesse cenário. As formas encontradas para essa atuação, ainda que possam ser descritas como uma renovação ou um novo fôlego para se pensar e agir politicamente, recuperam, na verdade, teorias que historicamente têm nutrido a formação de movimentos anarquistas libertários e socialistas, com ênfase nos anarquistas e autonomistas, com sua resistência contra o poder do Estado e as estruturas autoritárias de poder, e pelas práticas alternativas horizontais de participação e decisão (2014, p. 154).

A maior visibilidade do MPL diante de seu papel privilegiado nas manifestações de 2013 não pode obscurecer sua importante trajetória em momentos anteriores, quando jovens insatisfeitos com o verticalismo e a burocratização das organizações existentes optam pela criação do movimento (LIBERATO, 2006). Sob a égide de um modelo federativo, o MPL rapidamente se disseminou, constituindo núcleos em várias cidades do país, mas com desenhos diferentes quanto à capacidade de mobilização e de enraizamento nas lutas mais amplas.

A descentralização, a autonomia e a horizontalidade dos núcleos do MPL constituem um elemento importante para a compreensão dos modos diversos de engajamento e de concepção da própria prática, das tensões e dos conflitos que eventualmente nascem no interior dos grupos. Sousa (2014) aponta, em seu estudo sobre o MPL, o dissenso observado na questão de gênero protagonizado por núcleos radicados em São Paulo. Ainda sob o impacto dos eventos de junho de 2013, a partir de 2015, emergiram na cena pública, por meio de cartas e notas de militantes na Internet, debates relacionados à forma organizativa e à eventual ampliação das orientações já constituídas pelo MPL, implicando rupturas em momentos posteriores que afetaram a trajetória do movimento (HADDAD. 2016). 
Tendo em vista o caráter descentralizado e a proposta de ação direta no interior do ideário autonomista, além da defesa da horizontalidade nas práticas coletivas, chama a atenção uma produção emergente, mas significativa, realizada por ex-militantes, alguns criadores do movimento, como é o caso do trabalho pioneiro de Liberato (2006). Mais recentemente, viram-se trabalhos de militantes que ingressam no campo acadêmico e passaram a produzir conhecimentos relevantes sobre processos de construção da ação coletiva, que atravessaram os vários núcleos em cidades brasileiras. As análises desenvolvidas por Saraiva a partir de etnografia realizada com o núcleo do MPL de Brasília aprofundam as tensões e os desafios presentes na ideia da horizontalidade como marca distintiva das práticas, tendo em vista assegurar o consenso. Para a autora o dilema "todos somos líderes" ou "ninguém pode ser líder" indicaria a polarização dos afetos. De um lado a esperança e, de outro, o medo estariam presentes nas discussões internas do MPL e constituiriam dois lados da mesma moeda, uma vez que a métrica seria a mesma (SARAIVA, 2017, p. 312). Segundo a autora, há um "fluxo de distintas concepções" que desvelam diferenças significativas sobre a natureza do poder e da hierarquia. Incorpora, assim, no plano dos afetos, a ideia do desconforto e do desamparo, inspirada nos estudos de Safatle (2016). Diferenças de classe relativas a formação acadêmica, gênero e raça também ameaçariam a horizontalidade. Tais dilemas seriam traduzidos pela ambivalência, na medida em que "trazemos o mundo velho dentro de nós e ao mesmo tempo queremos ser o mundo novo" (SARAIVA, 2017, p. 320).

O LPJ, fundado em 2006, teve sua origem a partir de organizações diversas, sobretudo do MST, da Via Campesina e de militantes de partidos, sendo produto de deliberação nacional, mas com implantação descentralizada (SILVA; RUSKOWSKI, 2010). Desde sua origem, caracterizou-se pela tensão entre a presença permanente das organizações das quais é herdeiro e pela busca de autonomia. Em sua origem, percebe-se a atenção dada a novos temas, derivados das práticas coletivas de jovens, tanto no domínio da cultura como o movimento hip-hop, além das pautas que agregaram as lutas feministas e contra o racismo.

Tanto o MPL como LPJ foram também pouco investigados sob o ponto de vista de suas práticas educativas, uma vez que, constituídos, sobretudo, por jovens, despertaram apenas para alguns pesquisadores o interesse sobre possíveis continuidades e rupturas com o ideário da educação popular, presente nas lutas sociais, sobretudo no período da ditadura (HADDAD, 2016).

Entretanto, a busca de relações mais autônomas, revelando diferenças geracionais e tensões no interior dos movimentos, aparece também na mobilização dos jovens rurais, sendo mais nítido o campo de conflitos no interior do MST (CASTRO, 2009; MARTINS, 2009). Pouco estudados e marcados por uma forte invisibilidade, observa-se uma produção muito incipiente sobre esses sujeitos, que revela não só a adesão crítica a organizações e movimentos já consolidados, como novos formatos derivados, por exemplo, da Pastoral da Juventude Rural e da Juventude da Via Campesina, como os Grupos de Produção e Resistência (GPR), que constituem redes, tendo em vista a criação de mecanismos de geração de trabalho e renda por meio da agroecologia (ANDRADE et al., 2016) ${ }^{4}$.

Nas periferias das cidades, observa-se a constituição da ação coletiva por meio de pequenos grupos nos últimos anos, em grande parte submersos, os quais apresentam também uma recriação da dimensão territorial local que não se esgota nas práticas das denominadas culturas juvenis. Jovens recorrem a algumas associações de moradores já enraizadas ou organizações ligadas a grupos religiosos para desenvolverem ações em bairros e comunidades, ações essas entendidas por eles como parte de um engajamento político dotado de autonomia. É nelas que jovens encontram suporte tanto para iniciativas relativas à luta contra a violência como para a formação de ações de economia popular, entre as quais os bancos populares, além do desenvolvimento de ações culturais. Nessa experiência, mesclam-se os vários campos discursivos da ação política de décadas anteriores, como a ideia de "trabalho de base" e o trânsito das atividades desenvolvidas 
entre a assistência, o lazer e o ativismo político. Por outro lado, as interações com os territórios dominados por facções criminosas (os "manos") tornam o quadro do associativismo mais complexo, revelando mudanças importantes na configuração dos territórios periféricos e populares (MORENO, 2016).

As modalidades de ação voltadas para as questões identitárias e sua interseccionalidade com outras dimensões da opressão ${ }^{5}$ também constituem vetor de aglutinação e mobilização de jovens nos últimos anos, destacando-se o modo como esses segmentos encampam, tensionam e demandam espaços em movimentos tais como os feministas, LGBT+ e étnico-raciais.

Ainda pouco estudada, a dimensão geracional poderia evidenciar desde processos sociais a temporalidades alargadas nos processos de mobilização e de organização, sobretudo se considerarmos que alguns movimentos, como os feministas, ofereceram novidades importantes para dimensionar o conflito social e sua capacidade de ação na cena público-política (GONÇALVES; PINTO, 2011; ZANETTI, 2011).

A ênfase nos estudos das NTIC na mobilização dos jovens foi investigada, sobretudo, nos momentos do confronto político e da ocupação das ruas e praças. No entanto, se forem consideradas as formas organizativas iniciais de jovens LGBT+, por exemplo, o mundo virtual também se apresenta como locus de reconhecimento e explicitação de identidades, atuando nos momentos de invisibilidade ou latência (NUSSBAUMER, 2008, p. 214). Mesmo sendo provisória, para muitos, a adesão a essas comunidades virtuais permite romper o isolamento, abrindo alternativas para as interações no mundo off-line e para a integração em atividades coletivas, podendo constituir nexos com o próprio movimento LGBT+ (TOMIZAKI; DANILIAUSKAS, 2018).

A disseminação de coletivos de jovens negros, organizados a partir de demandas de igualdade, contra o racismo e a violência que afeta de modo mais forte esse grupo, constituem novo vetor para a investigação, uma vez que os coletivos de mulheres negras já ocupam a cena pública há algumas décadas. Do mesmo modo, são raros os estudos de iniciativas coletivas de jovens em torno das questões ambientais, examinadas por Bacelar e Castro (2016) sob o ângulo das alterações subjetivas de jovens que participam de movimentos ambientalistas plurais no estado do Rio de Janeiro.

As práticas aqui examinadas trazem, apesar de sua diversidade, ênfases e críticas diferenciadas nas interações com as denominadas organizações tradicionais, como sindicatos e partidos políticos. O espectro revela de uma recusa explícita até uma convivência pontuada por tensões, em que se registra claramente a busca de uma convivência que assegure a autonomia dos grupos envolvidos.

Por outro lado, os movimentos e organizações que expressam com maior visibilidade sua presença nos ciclos de protesto político, como o MPL e LPJ, são menos investigados nos modos como constroem suas ações em outros momentos, compreendendo as tensões, continuidades e rupturas que envolvem as orientações defendidas. Os coletivos de feição identitária - gênero, raça e orientação sexual - e os grupos de jovens imersos em práticas oriundas de um forte vínculo com a dimensão territorial são examinadas a partir de estudos específicos, muitas vezes reconstruindo seus modos de ação nas formas submersas. De modo paradoxal, é pouco visível a interação desses atores no interior dos ciclos de mobilização e de protesto político, quando múltiplos protagonistas ocupam as ruas e praças.

\section{Considerações Finais}

Os estudos realizados no Brasil nas décadas de 2000 e 2010 evidenciaram formatos múltiplos e diversos da ação coletiva de jovens. No entanto, além do reconhecimento dessa significativa pluralidade seria preciso avançar na compreensão dos desenhos da ação coletiva que envolve jovens. Um recurso comum nas interpretações tem sido o uso amplo, não raro como sinônimo, de categorias como movimentos 
sociais, grupos, organizações, culturas juvenis e coletivos. No âmbito da teoria dos movimentos sociais, as mobilizações observadas a partir dos anos 2000 tendem a ser compreendidas como "novos" ou "novíssimos movimentos sociais" quando a análise procura evidenciar as inovações e rupturas. No entanto, mudanças e continuidades ocorrem em qualquer formato de movimentos; as classificações, muitas vezes, não elucidam processos que estão sendo desenhados na ação coletiva dos sujeitos e exprimem tendências emergentes. Por outro lado, a horizontalidade e a busca de autonomia diante das organizações tradicionais, apontadas em alguns estudos como traços caracterizadores do que se designa como "novíssimos movimentos sociais", já estavam presentes em ideários próximos do anarquismo desde o século XIX, em alguns momentos da história do movimento feminista e em setores independentes do movimento estudantil.

O recurso à noção de movimentos sociais, como afirma Touraine (2006), torna-se importante como elemento de análise que possa contribuir para a compreensão das dimensões conflitivas e das relações de dominação na sociedade contemporânea, mas não pode ser confundida com a ideia de participação política, também relevante para o estudo das formas de ação coletiva. Por outro lado, Bringel (2018) indica que a análise contemporânea enfrenta questões emergentes:

o primeiro desafio aqui tem a ver com o descentramento da forma-movimento clássica. Como podemos repensar a "forma movimento" que nos acompanhou até hoje em um momento marcado pela tendência à existência de fronteiras cada vez mais tênues nas organizações e nos coletivos? (2018, p. 26).

Entretanto, para além do escrutínio analítico realizado pelos investigadores, seria importante compreender concepções e usos de certas noções utilizadas pelos próprios atores em suas formas de mobilização. Trata-se do reconhecimento da importância das categorias nativas - autodefinição, na indicação de Bringel (2018) -, que perfilam horizontes de significados e de práticas em sua historicidade, mais do que pressupostos imutáveis que orientam os grupos e movimentos. Uma importante inflexão, reconhecida nos estudos, mas ainda pouco investigada, diz respeito aos formatos da ação já presentes desde o início dos anos 2000, mas com maior intensidade nos últimos anos, em que jovens optam por designar, preferencialmente, seu pertencimento mais a coletivos e menos a movimentos, organizações ou associações. Esmiuçar de modo mais analítico a ideia de coletivos, além de considerar categorias descritivas como eixos temáticos agregadores - os graus de institucionalização, a horizontalidade nas interações, o caráter mais ou menos fluído das práticas -, poderá indicar como e por que esses atores sentem-se mais bem-representados a partir da ideia de coletivos do que por outros modos de sua designação. Que tendências esses formatos enunciam? Ao mesmo tempo, como desafiam a compreensão para eventual renovação das categorias analíticas que subsidiaram os estudos dos movimentos sociais?

Dois outros elementos poderão ser escrutinados em sua historicidade, na medida em que foram centrais na discussão dos movimentos sociais: a construção das identidades coletivas e a dimensão conflitiva das práticas.

Os processos identitários, ao refletirem práticas de pequenos grupos, contemplam as mesmas dimensões presentes nos estudos dos movimentos sociais? Como são articulados os processos de constituição de um "nós", recorrentes nos estudos sobre movimentos sociais, com a mediação das singularidades e individualidades na contemporaneidade como traços presentes na experiência dos atores? Para Bringel (2018), as mutações na constituição das identidades coletivas seriam as dimensões que mais perfilaram mudanças nos últimos anos. Urge, também, acionar o estudo de afetos e emoções, ainda pouco incorporado na produção brasileira sobre os atores jovens em suas mobilizações. Esses aspectos estão presentes na conformação das identidades, propiciando novas modalidades agregativas ao lado de tensões recorrentes nas práticas e nas interações dos sujeitos (MELUCCI, 2001; JASPER, 2011; GOODWIN et al., 2000; REBUGHINI; SCRIBANO, 2018). 
Todavia, há também tendências no interior dos formatos de mobilização de jovens no interior de suas práticas, que sugerem as recorrências de deslocamentos, quer para ingressar em outros grupos já existentes, quer para criar novos desenhos. Marcadas por perspectivas mais lineares ou enfatizando permanências, muitas vezes as análises não incorporam a descontinuidade dos tempos da vida coletiva, sobretudo nas condições atuais. Examinar os deslocamentos que, sob o ponto de vista interno a um agrupamento, pode significar desafecção ou desengajamento, na experiência dos atores envolvidos, pode significar experimentações e aberturas para novas práticas. Aqui, abre-se um campo ainda pouco explorado que pode ser traduzido nos modos de constituição dos jovens como atores coletivos nas tensões e possibilidades que marcam as sociedades individualistas, atravessadas por singularidades que produzem e são produzidas pelo mundo social (MARTUCCELLI, 2010). Como afirma Mendonça (2017, p. 138), é preciso reconhecer que as formas mais individualizadas de engajamento político não se submetem à díade "indivíduo-coletivo", estando mais próximas da formulação "singular-comum".

O segundo elemento importante das teorias sobre os movimentos sociais - a natureza do conflito - não pode ser depreendido como decorrência de elementos presentes em torno de ideologias muito elaboradas, em geral recorrendo aos conflitos fundamentais na sociedade. Tais ideologias não constituem, obrigatoriamente, manifestações práticas de antagonismos sociais (TOURAINE, 2006). Para o autor, movimentos e seus conflitos colocam em causa modos generalizados de dominação, ainda que explicitem, na cena pública, questões a partir de domínios socialmente definidos.

A dimensão territorial na arena dos conflitos sociais (SVAMPA, 2009) tem oferecido fértil possibilidade para dar conta da emergência e da consolidação de práticas de jovens moradores de bairros periféricos ou comunidades pobres desde os anos 1990, mas que atualmente amplificam-se para incluir os agrupamentos nascidos no interior de praças e locais públicos da cidade, estabelecendo um revigoramento tanto da ideia do direito à cidade (LEFEBVRE, 1978; FRÚGOLI, 2018) como da emergência de novas ruralidades, entre jovens que buscam criar caminhos próprios para sua mobilização política.

Por outro lado, um elemento a ser considerado é o estudo das conexões entre os formatos da ação, ou seja, se, como e quando os coletivos, grupos ou movimentos exercitam interações e trocas. Como se dão os laços/tensões nos momentos do confronto político ou nos interstícios das práticas cotidianas? A constituição de redes de coletivos, de movimentos ou organizações juvenis, não está pressuposta a priori, como derivação necessária das mobilizações. Ela é produto permanente das possibilidades e impossibilidades gestadas pelos atores mobilizados em contexto de uso intensivo das tecnologias e das redes sociais. As conexões fortalecem as trocas e a formação de redes ou as novas práticas tendem a erguer fronteiras espessas que privilegiam apenas mecanismos internos de solidariedade, produzindo segmentações, isolamento e segregação? Que conflitos e tendências estão presentes na constituição de um espaço comum de práticas, tendo como cenário a emergência de coletividades-singulares?

Trata-se, sob esse ponto de vista, de um desafio teórico-investigativo relevante diante do que alguns estudos evidenciam como os trajetos marcados por constrangimentos para a constituição de um mundo comum na esfera pública. Como afirma Tassin (1992),

“[d]evemos compreender que o mundo comum é a condição da possibilidade de uma polis, da instituição de um espaço público e, ao mesmo tempo, é somente a instituição desse espaço que possibilita um mundo comum, é somente sob a condição de um domínio público que o mundo pode ser comum (1992, p. 36; tradução livre $)^{6}$.

O “comum" não só é recoberto pela diversidade de indivíduos e de grupos, mas se desvela, também, pela confluência plural e conflitiva dos modos da ação coletiva nos espaços públicos (MOUFFE, 1993). 


\section{Contribuição dos Autores}

Problematização e conceitualização: Sposito MP, Almeida E, Corrochano MC; Metodologia: Sposito MP, Almeida E, Corrochano MC; Análise: Sposito MP, Almeida E, Corrochano MC; Redação:Sposito MP, Almeida E, Corrochano MC.

\section{Notas}

1. Foram considerados todos os artigos publicados entre os anos de 2007-2017 nos periódicos classificados pelo Sistema Qualis Capes como A1, A2, B1 e B2 nesse período. O ano de 2018 foi incorporado posteriormente, além de extensa bibliografia complementar constituída por livros ou artigos publicados em outros periódicos.

2. No original: "no es una realidad 'externa' a los sujetos colectivos, y como tal no está al margen de los procesos cognitivos e interpretativos que despliegan sus integrantes, o sea, de los procesos de construcción de sentido" (PINEDA, 2016, p. 196).

3. Assassinato do adestrador de cães Edson Neris da Silva.

4. Em 2016, a REDE GPR contava com 597 jovens, integrando 61 grupos, nos estados da Bahia, do Ceará, do Espírito Santo, da Paraíba, de Pernambuco, do Rio Grande do Norte e de Sergipe.

5. Neste dossiê, o artigo "Movimentos feminista, negro e LGBTI no Brasil: sujeitos, teias e enquadramentos" examina essas questões, resgatando sua dimensão histórica.

6. No original: "Il nous faut comprendre que le monde commun est la condition de possibilité d'une polis, de l'institution d'un espace public et, en meme temps, que c'est seulement l'institution de cet espace qui rend possible un monde commun, que cest seulement a condition d'un domaine public que le monde peut etre commun" (TASSIN, 1992, p. 36).

\section{Referências}

ABRAMO, H. W. Considerações sobre a tematização social da juventude no Brasil. Revista Brasileira de Educação, ANPEd, n. 5, 6, 7, 1997.

ADERALDO, G. Linguagem audiovisual e insurgências populares: Reconstituindo uma experiência associativa entre jovens vídeo-ativistas nas "periferias" paulistanas. Iluminuras, v. 18, n. 44, p. 74-101, jan.-jul. 2017. doi: https://doi.org/10.22456/1984-1191.75734

ALMEIDA, E. Os estudos sobre grupos juvenis: presenças e ausências. In: SPOSITO, M. P. (coord.). O estado da arte sobre juventude na pós-graduação brasileira: Educação, Ciências Sociais e Serviço Social (19992006). Belo Horizonte: Argumentum, 2009, v. 2, p. 121-174.

ALMEIDA, R. C.; PENZIN, A. M. B. Novos coletivos urbanos e as expressões de lutas emancipatórias: Os saraus em Belo Horizonte. In: XIII Congresso Luso-Afro-Brasileiro de Ciências Sociais, São Paulo, 2018. 
Anais do XIII CONLAB, África, Diásporas, Diálogos Sul-Sul São Paulo: Descolonizando as Ciências Sociais e Humanas, São Paulo: UNIFESP, 2018.

ALONSO, A.; MISCHE, A. Changing repertoires and partisan ambivalence in the new Brazilian protests. Bulletin of Latin American Research, v. 36, n. 2, p. 144-159, 2017. https://doi.org/10.1111/blar.12470

AMARAL, J. G. Coletivos universitários de diversidade sexual e a crítica à institucionalização da militância LGBT. Revista de Ciências Sociais, v. 4, n. 2, p. 133-179, jul.-dez. 2014. http://doi.org/10.5902/2236672517041

ANDRADE, G. S.; MANSAN, P. R. A.; TROILO, G. Juventude da via campesina: Da invisibilidade à construção da rede GPR. Entrelaçando, ano V, n. 10, 2016.

BACELAR, R; CASTRO, L. R. Modos de subjetivação de jovens em um território de conflito socioambiental. Psicologia \& Sociedade, v. 28, n. 3, p. 463-472, 2016. https://doi.org/10.1590/1807-03102016v28n3p463

BARBOSA, F. S.; BRUM, C. K. O vazio ocupa um espaço imenso: Ocupações secundaristas e as habilidades necessárias para se mover na crise. Revista Cadernos de Campo, n. 25, p. 245-267, jul.-dez. 2018.

BARROS, C. P. P. Contestando a ordem: Um estudo de caso com secundaristas da Zona Leste Paulista. 2017. Dissertação (Mestrado em Ciência Política) - Programa de Pós-graduação em Ciência Política, FFLCH, Universidade de São Paulo, São Paulo, 2017. 217p.

BORELLI, S. H. S.; ABOBOREIRA, A. Teorias/metodologias: Trajetos de investigação com coletivos juvenis em São Paulo/Brasil. Revista Latinoamericana de Ciencias Sociales, Niñez y Juventud, v. 1, n. 9, p. 161172, 2011.

BRINGEL, B. O futuro anterior: Continuidades e rupturas nos movimentos estudantis no Brasil. EccoS Revista Científica, v. 11, n. 1, p. 97-121, jan.-jun. 2009. https://doi.org/10.5585/eccos.v11i1.1529

BRINGEL, B. Crisis política y polarización en Brasil: De las protestas de 2013 al golpe de 2016. In: BRINGEL, B.; PLEYERS, G. Protesta e indignación global, Buenos Aires: CLACSO, 2017, p. 141-154.

BRINGEL, B. Mudanças no ativismo contemporâneo: controvérsias, diálogos e tendências. In: FASE (ed.). A luta popular urbana por seus protagonistas: Direito à cidade, direitos nas cidades. Rio de Janeiro: FASE, 2018. BRINGEL, B; PLEYERS, G. June 2013, five years later: Polarization, reconfiguration of activism, and challenges for the Brazilian left. In: PUZONE, V.; MIGUEL, L. F. (eds.). The Brazilian left in the 21st century. Conflict and conciliation in peripheral capitalism. London: Palgrave Mc Millan, 2019, p. 237-258. https:// doi.org/10.1007/978-3-030-03288-3_11

BUCCI, E. A forma bruta dos protestos. Das manifestações de junho de 2013 à queda de Dilma Rousseff em 2016. São Paulo: Companhia das Letras, 2016.

CALDEIRA, T. P. R. Inscrição e circulação: Novas visibilidades e configurações do espaço público em São Paulo. Novos Estudos, n. 94, nov. 2012. https://doi.org/10.1590/S0101-33002012000300002

CALDEIRA, T. P. R. Qual a novidade dos rolezinhos? Espaço público, desigualdade e mudança em São Paulo. Novos Estudos, n. 98, mar. 2014. https://doi.org/10.1590/S0101-33002014000100002

CAMPOS, M. A.; MEDEIROS, J.; RIBEIRO, M. M. Escolas de luta. São Paulo: Veneta, 2016. 
CARRANO, P. C. R. Jovens universitários. In: SPOSITO. M. P. (coord.). Juventude e Escolarização. Brasília: MEC/INEP/Comped, 2002, p. 135-155.

CASTILHO, F.; ROMANCINI, R. Minas de luta na mídia: Enquadramentos e percepções das ocupações escolares em São Paulo. Brazilian Journalism Research, v. 14, n. 1, p. 282-305, abr. 2018.

CASTRO, E. G. Juventude rural no Brasil: Processos de exclusão e a construção de um ator político. Revista Latino-americana de Ciências Sociais, v. 7, n. 1, jan.-jun. 2009.

CATINI, C. R.; MELLO, G. M. C. Escolas de luta, educação política. Educação \& Sociedade, v. 37, n. 137, p. 1177-1202, out.-dez. 2016. https://doi.org/10.1590/es0101-73302016163403

CORTI, A. P. O.; CORROCHANO, M. C.; SILVA, J. A. "Ocupar e resistir": a insurreição dos estudantes paulistas. Educação \& Sociedade, vol. 37, n.137, pp.1159-1176, out.-dez. 2016. https://doi.org/10.1590/ es0101-73302016167337

COSTA, M. R. “Carecas do subúrbio”: Caminhos de um nomadismo moderno. Petrópolis: Vozes, 1993.

DUBET, F. La galère: Les jeunes en survie. Paris: Fayard, 1987.

FACCHINI, R. "Não faz mal pensar que não se está só": estilo, produção cultural e feminismo entre as minas do rock em São Paulo. Cadernos Pagu, 36, p. 117-153, jan.- jun. 2011. https://doi.org/10.1590/ S0104-83332011000100006

FEIXA PAMPOLS, C.; NOFRE, J. Youth Culture, In: KLANDERMANS, B. (ed.). Sociopedia. London: Sage, 2012.

FEIXA PAMPOLS, C.; OLIVEIRA; V. H. N.; LACERDA, M. P. C.; SANTOS, A. M. Culturas juvenis e temas sensíveis ao contemporâneo: uma entrevista com Carles Feixa Pampols. Educar em Revista, v. 34, n. 70, p. 311-325, jul.-ago. 2018. https://doi.org/10.1590/0104-4060.58145

FORACCHI, M. O estudante e a transformação da sociedade brasileira. São Paulo: Nacional, 1965.

FORACCHI, M. A juventude na sociedade moderna. São Paulo: Pioneira, 1972.

FRÚGOLI, H. Ativismos urbanos em São Paulo. Cadernos CHR, v. 31, n. 82, p. 75-86, 2018. https://doi. org/10.1590/s0103-49792018000100005

GOHN, M. G. Jovens e as praças dos indignados. Revista Brasileira de Sociologia, v. 1, n. 2, p. 205-222, jul.dez. 2013. https://doi.org/10.20336/rbs.48

GOHN, M. G. A sociedade brasileira em movimento: Vozes das ruas e seus ecos políticos e sociais. Caderno CRH, v. 27, n. 71, p. 431-441, 2014. https://doi.org/10.1590/S0103-49792014000200013

GOHN, M. G. Manifestações e protestos no Brasil: Correntes e contracorrentes na atualidade. São Paulo: Cortez, 2017. GOODWIN, J.; JASPER, J.; POLLETTA, F. The return of the repressed: The fall and rise of emotions in social movement theory. Mobilization: An International Journal, v. 5, n. 1, p. 65-83, 2000.

GONÇALVES, E; PINTO, J. Reflexões e problemas da "transmissão" intergeracional no feminismo brasileiro. Cadernos Pagu, v. 36, p. 25-46, jan.-jun. 2011. https://doi.org/10.1590/S0104-83332011000100003

GROPPO, L. A.; TREVISAN Jr., R. F.; BORGES, L. F.; BENETTI, A. M. Ocupações no sul de Minas: Autogestão, 
formação política e diálogo intergeracional. ETD - Educação Temática Digital, v. 19, n. 1, p. 141-164, jan.mar. 2017. https://doi.org/10.20396/etd.v19i1.8647616

GROPPO, L. A.; TREVISAN Jr., R. F.; BORGES, L. F.; BENETTI, A. M. O novo ciclo de ações coletivas juvenis no Brasil. In: COSTA, A. A. F.; GROPPO, L. A. O movimento de ocupações estudantis no Brasil. São Carlos: Pedro \& João Editores, 2018.

HADDAD, S. Novas formas de ativismo social: O que há por trás das mobilizações de rua? O Movimento Passe Livre de São Paulo (MPL-SP). Revista e-Curriculum, v. 14, n. 2, p. 572-601, abr.-jun. 2016.

HOLSTON, J. Cidadania insurgente: Disjunções da democracia e da modernidade no Brasil. São Paulo: Companhia das Letras, 2013.

JASPERS, J. Emotions and social movements: Twenty years of theory and research. The Annual Review of Sociology, v. 37, p. 285-303, 2011. https://doi.org/10.1146/annurev-soc-081309-150015

LEFEBVRE, H. El derecho a la ciudad. Barcelona: Península, 1978.

LEITE, M. No colégio dos alunos, por alunos, para alunos: feminismo e desconstrução em narrativas das ocupações. ETD - Educação Temática Digital, v. 19, n. especial, p. 23-47, jan.-mar. 2017. doi: https://doi. org/10.20396/etd.v19i0.8647807

LIBERATO, L. V. M. Expressões contemporâneas de rebeldia: Poder e fazer da juventude autonomista. Tese (Doutorado em Sociologia Política) - Centro de Filosofia e Ciências Humanas, Universidade Federal de Santa Catarina. Florianópolis, 2006.

MEDAETS, C.; MÉZIÉ, N.; CARVALHO, I. "De cabeça e com o coração”: O fazer política de jovens ocupantes das escolas estaduais de Porto Alegre (maio e junho 2016). In: FONSECA, C.; MEDAETS, C.; RIBEIRO, F. B. Pesquisas sobre família e infância. Porto Alegre: Sulina, 2018, p. 130-152.

MARTINS, S. A. M. A formação política da juventude do movimento sem-terra no estado do Paraná. 2009. Tese (Doutorado em Sociologia Política) - Universidade Federal de Santa Catarina, Florianópolis, 2009.

MARTUCCELLI, D. La société singulariste. Paris: Armand Colin, 2010.

McROBBIE, A.; GARBER, J. (1975) Girls and subcultures. In: STUART, H.; JEFFERSON, T. (eds). Resistance through ritual: Youth subcultures in post-war Britain. London: Taylor \& Francis e-Library, 2003.

MENDONÇA, R. F. Singularidade e identidade nas manifestações de 2013. Revista do Instituto de Estudos Brasileiros, n. 66, p. 130-159, abr. 2017. doi: https://doi.org/10.11606/issn.2316-901x.v0i66p130-159

MENDONÇA, R. F. Dimensões democráticas nas jornadas de junho: Reflexões sobre a compreensão de democracia entre manifestantes de 2013. Revista Brasileira de Ciências Sociais, v. 33, n. 98, 2018. https:// doi.org/10.1590/339707/2018

MENDONÇA, R. F.; COSTA, M. B. Back to the future? Changing repertoire in contemporary protests. I Congresso do INCT-DD, 19-21 set. 2018, Salvador, Bahia. https://doi.org/10.1111/blar.13087

MEDEIROS, L.; MOREIRA, V. S.; SOARES, M. G.; MARTINS, S. Representatividade em coletivos estudantis: análise com base nas relações estabelecidas no contexto universitário. Revista de Ciências Humanas, v. 17, n. 1, p. 160-181, jan.-jun. 2017. 
MELUCCI, A. A invenção do presente: Movimentos sociais nas sociedades complexas. Petrópolis: Vozes, 2001.

MELUCCI, A. Juventude, tempo e movimentos sociais. Revista Brasileira de Educação, n. 5-6, p. 5-14, mai.-dez. 1997.

MESQUITA, M. R. Movimento estudantil brasileiro: práticas militantes na ótica dos novos movimentos sociais. Revista Crítica de Ciências Sociais, n. 66, p. 117-149, out. 2003. https://doi.org/10.4000/rccs.1151

MESQUITA, M. R. Cultura e política: A experiência dos coletivos de cultura no movimento estudantil. Revista Crítica de Ciências Sociais, n. 81, p. 179-207, 2008. https://doi.org/10.4000/rccs.660

MORENO, G. G. Militantes, irmãos e cabos eleitorais: Vida associativa e território nas periferias da cidade de São Paulo. Mana, v. 22, n. 2, p. 403-434, 2016. https://doi.org/10.1590/1678-49442016v22n2p403

MORENO, R. C; ALMEIDA, A. M. F. Quando jovens ativistas do hip-hop encontram a política partidária. Revista de Sociologia e Política. v. 25, n. 61, p. 5-29, mar. 2017. https://doi.org/10.1590/1678-987317256101

MOUFFE, C. The return of the political. London: Verso, 1993.

NOVAES, R.; ALVIM, R. Movimentos, redes e novos coletivos juvenis: Um estudo sobre pertencimentos, demandas e políticas públicas de juventude. In: LOPES, J. S. L.; HEREDIA, B. M. A. Movimentos sociais e esfera pública. Rio de Janeiro: CBAE, 2014, p. 269-303.

NUSSBAUMER, G. Identidade e sociabilidade em comunidades virtuais gays. Revista Bagoas - Estudos gays, gênero e sexualidades, v. 8, n. 11, jul.-dez. 2008.

OLIVEIRA, G. S. Políticas racializadas e o surgimento de coletivos de estudantes negros no Ensino Superior. In: REUNIÃO BRASILEIRA DE ANTROPOLOGIA, n. 31, 2018. Brasília, Anais da 31 ${ }^{\mathbf{a}}$ RBA - Direitos humanos e antropologia em ação. Brasília: UnB, 2018.

PEREIRA, A. B. Os "rolezinhos" nos centros comerciais de São Paulo: Juventude, medo e preconceito. Revista Latinoamericana de Ciencias Sociales, Niñez y Juventud, v. 14, n. 1, p. 545-557, 2016.

PEREZ, O. C.; SOUZA, B. M. Velhos, novos ou novíssimos movimentos sociais? As pautas e práticas dos coletivos. In: 41 ENCONTRO ANUAL DA ANPOCS, Anais. Caxambu, 2017.

PINEDA, E. K. El carácter multidimensional de la acción colectiva y los movimientos sociales: una problematización teórica. Secuencia, n. 95, p. 188-214, may.-ago. 2016. http://doi.org/10.18234/secuencia. v0i95.1382

PINHEIRO-MACHADO, R.; SCALCO, L. M. Rolezinhos: Marcas, consumo e segregação no Brasil. Revista de Estudos Culturais, v. 1, n. 1, 2014.

PINHEIRO-MACHADO, R.; SCALCO, L. M. Da esperança ao ódio: A juventude periférica bolsonarista. In: GALLEGO, E. S. O ódio como política. A reinvenção das direitas no Brasil. São Paulo: Boitempo, 2018. p. 53-59.

POSSAS, L. M. V.; FRANÇA, C. E. As múltiplas significações de gênero: reflexões a partir da violência e da exacerbação de masculinidade de um grupo de skinheads paulista. Espaço Plural, v. 10, n. 21, p. 97-104, 2009. 
RAMOS, I. N. Funkeiras e hip-hoppers, mulheres artistas em movimento. Revista de Antropologia e Arte, v. 1, n. 7, p. 180-188, jan.-jun. 2017.

RATTO, C. G. R.; GRESPAN, C. L.; HADLER, O. H. Ocupa $1^{\circ}$ de maio: Ciberdemocracia, cuidado de si e sociabilidade na escola. ETD - Educação Temática Digital, v. 19, n. 1, p. 99-118, jan.-mar. 2017. https://doi. org/10.20396/etd.v19i1.8647733

REBUGHINI, P.; SCRIBANO, A. Embodied emotions between constructivism and ontologism. A reflection from the sociology of Alberto Melucci. Social Science Information, n. 10, p. 1-18, 2018. https://doi. org/10.1177/0539018418802995

REGUILLO, R. Emergencia de culturas juveniles: Estrategias del desencanto. Bogota, Grupo Editorial Norma, 2000.

REGUILLO, R. Paisajes inssurectos jóvenes: Redes y revueltas en el otoño civilizatorio. Barcelona: NED Ediciones, 2017.

SAFATLE, V. O circuito dos afetos: Corpos políticos, desamparo e o fim do indivíduo. Belo Horizonte: Autêntica Editora, 2016.

SANFELICE, J. L. Movimento estudantil: A UNE na resistência ao golpe de 1964. São Paulo: Cortez, 1986.

SARAIVA, L. Para além das palavras: Teorias e práticas da horizontalidade como construção de utopias no Movimento Passe Livre-DF, Belo Horizonte, Revice - Revista de Ciências do Estado, v. 2. n. 1, p. 296-326, jan.-jul. 2017.

SILVA, M. K.; RUSKOWSKI, B. O. Levante juventude, juventude é prá lutar: Redes interpessoais, esferas de vida e identidade na constituição do engajamento militante. Revista Brasileira de Ciência Política, Brasília, n. 3, p. 23-48, jan.-jul. 2010.

SOLANO, E.; MANSO, B. P.; NOVAES, W. Mascarados. A verdadeira história dos adeptos da tática Black Bloc. São Paulo: Geração Editorial, 2014.

SOUSA, J. T. P. A experiência contemporânea da política entre jovens do sul do Brasil. Buenos Aires, CLACSO, 2014.

SPOSITO, M. P. A sociabilidade juvenil e a rua: novos conflitos e ação coletiva na cidade. Tempo Social, v. 5, n.1-2, p. 161-178, 1993. https://doi.org/10.1590/ts.v5i1/2.84954

SVAMPA, M. Protesta, movimientos sociales y dimensiones de la acción colectiva en América Latina, 2009. Disponível em: < http://www.maristellasvampa.net/archivos/ensayo57.pdf>. Acesso em: 06 ago. 2019.

TASSIN, E. Espace commun ou espace public? Lantagonisme de la communauté et de la publicité. Hermès, La Revue, n. 10, p. 23 -37, 1992.

TOMIZAKI, K.; DANILIAUSKAS, M. A pesquisa sobre educação, juventude e política: reflexões e perspectivas. Revista Pro-posições, v. 29, n. 1, p. 214-238, jan.- abr. 2018. https://doi.org/10.1590/1980-6248-2016-0126

TOURAINE, A. Na fronteira dos movimentos sociais. Sociedade e Estado, v. 21, n. 1, p. 17-28, jan.-abr. 2006. https://doi.org/10.1590/S0102-69922006000100003 
WELLER, W. A presença feminina nas (sub)culturas juvenis. Estudos Feministas, v. 113, n. 1, p. 107-126, jan.-abr. 2005. https://doi.org/10.1590/S0104-026X2005000100008

ZANETTI, J. Jovens feministas do Rio de Janeiro: Trajetórias, pautas e relações intergeracionais. Cadernos Pagu, n. 36, p. 47-75, jan.-jun. 2011. https://doi.org/10.1590/S0104-83332011000100004

\section{Sobre os Autores}

Marilia Pontes Sposito é professora Titular da Faculdade de Educação (FEUSP) - Programa de Pósgraduação em Educação - Departamento de Filosofia da Educação e Ciências da Educação - Grupo de Estudos em Temas de Sociologia da Educação (GETESE).

Elmir de Almeida é graduado (1986) em Pedagogia pela Universidade de São Paulo (USP); Mestre (1996) e Doutor (2001) em Educação também pela USP. Docente da Faculdade de Filosofia, Ciências e Letras de Ribeirão Preto da USP. Tem experiência na área de Educação com ênfase em Sociologia da Educação.

Maria Carla Corrochano é professora Doutora do Centro de Ciências Humanas e Biológicas (CCHB) Programa de Pós-graduação em Educação e do Programa de Estudos em Condição Humana- Departamento de Ciências Humanas e Educação (DCHE) - Grupo de Estudos: Gerações, Percursos de Vida e Processos Educativos.

Recebido: 14 Nov 2019 Aceito: 27 Jan 2020 